
\title{
A Methodology for Energy Simulation of Residential Buildings: A Case Study for Amman
}

\author{
${ }^{*}$ Ahmad Altarabsheh, ${ }^{2}$ Ibrahim Altarabsheh, ${ }^{3}$ Sara Altarabsheh, ${ }^{4}$ Nisreen rababaa, ${ }^{4}$ Ayat Smadi, ${ }^{4}$ Doha obeidat \\ ${ }^{* 1}$ Faculty of Engineering, Department of Civil Engineering, Yarmouk university, Irbid, Jordan \\ 2 Program Manager, Jordan Pioneer for Metal Industry, Amman, Jordan \\ Project coordinator, Technical Aqrab Contracting Group, Amman, Jordan \\ ${ }^{4}$ Bachelor Students, Department of Civil Engineering, Yarmouk university, Irbid, Jordan
}

\begin{abstract}
Green buildings have been gaining in popularity in Jordan over the past few years. This is attributed to environmental and financial reasons directly related to energy consumption and cost. Energy sector in Jordan faces two main challenges which are the fast growing of energy demand and the scarcity of resources to fulfill this demand. Green buildings can save energy by designing them as zero or near Zero Energy Buildings, where they produce amount of energy equal or almost equal the amount of energy they consume. Despite these benefits of green buildings, they are not yet the norm in the building sector in Jordan. This paper aims to provide real life cycle cost analysis for a typical residential building in Jordan, and to search different effective building strategies that will lead to a successful near Zero Energy Building. The outcome of this study is a list of best economically feasible design solutions that result in near Zero Energy Building.
\end{abstract}

Key words: Energy simulation, zero energy building, residential building

\section{Introduction}

Rapid growth of population in Jordan during the past few years largely increase the demand on fossil energy in the country. However, the very limited sources of fossil energy in Jordan force the government to import about $96 \%$ of its demand. This nearly complete reliance on imported foreign oil requires about $18 \%$ of the annual gross domestic product (GDP) in the country. Moreover, multiple attacks on the Arab Gas Pipeline from 2011 to 2014, which supplied 88\% of the country's electricity generation needs, forced the country's power plants onto diesel and heavy fuel oil, costing the treasury millions and pushing the national energy bill to record highs. All these factors have left Jordan struggling to meet its energy requirements. [1] stated that energy consumption in Jordan is increasing at a higher rate than country GDP, which is opposite to the trend in the most countries in the world. [2] discussed that investment in energy infrastructure will account for more than 3 percent of GDP by 2030, versus 1 percent for the rest of the world. Therefore, such rapid growth in energy consumption will have negative impact on the country's economic.

Residential buildings consume up to $24 \%$ of the total energy consumed in Jordan and about $42 \%$ of the total consumed electricity [3]. The use of solar energy is one of promising renewable energy resources in Jordan that can be used to generate electricity in residential buildings and

*Corresponding author: Address: Faculty of Engineering, Department of Civil Engineering Yarmouk University, 21163, Irbid Jordan. E-mail address: ahmad.gt@yu.edu.jo, Phone: + 9622721111 
reduce their dependency on fossil energy. [4] discussed that Jordan location makes it attractive for harvesting solar energy since it has approximately 300 sunny days annually with an average annual irradiation of $2080 \mathrm{kWh} / \mathrm{m} 2$. Despite the benefits of using solar energy, it still unpopular in Jordan. [5] stated that currently solar and wind energy only contributes up to $4 \%$ of the national electricity grid. Government issued few laws to increase the use of renewable energy to generate electricity. One of these laws was the Law No. 13 of 2012 that allows people to sell electricity they produced from renewable sources to electricity companies. In addition to this law, the government set a target to increase the amount of electricity generated from renewable energy by $10 \%$ at the end of 2020 . Finally, the government issued energy efficiency programs that force designers to comply with the insulation requirements of the Jordanian Thermal Insulation Code (JNBC 2009) [6] and encouraged investors to invest in green buildings by exempting them from construction fees. [7] discussed that there is extreme needs to design and construct the new buildings in Jordan according to national and international obligations to achieve zero or near zero energy performance.

The objective of this study is to assess the effectiveness of near zero energy residential buildings in Jordan in term of their life cycle cost. This purpose is achieved by evaluating cost effectiveness of different construction strategies and design scenarios that will lead to a successful near Zero Energy Buildings. Therefore, this study helps decision makers to set economic and environmental intervention policy on a national level. Also, this study introduces both architects and engineers to broad range of design alternatives that reduce energy consumption by residential buildings. This helps in embedding the concept of near zero green buildings in the regional context and better adapting it to engineering practice.

\section{Background}

The definition of Zero Energy Buildings (ZEBs) were first discussed by almost 20 countries at the $40^{\text {th }}$ task of the International Energy Agency (IEA) in 2008 [8]. Also, both united states and European countries discussed the definition of ZEBs separately within the Energy Independence and Security Act of 2007 and the Energy Performance of Buildings Directive (EPBD) adopted in May 2010 respectively [9], [10]. [11] discussed that definition of ZEBs depending on different market interpretations, therefore, there is no international agreement on one definition for ZEBs. However, one of most common definition for ZEBs is the one introduced by the report prepared by [12], which defines ZEB as "the building that produces enough renewable energy to meet its own annual energy consumption requirements, thereby reducing the use of non-renewable energy in the building sector. ZEBs use all cost-effective measures to reduce energy usage through energy efficiency and include renewable energy systems that produce enough energy to meet remaining energy needs.".

On the other hand, the recast of EPBD introduces the concept of near zero energy building (NZEB), where buildings produce large portion of the energy they consumed, instead of achieving balance between the produced and the consumed energy as the case for ZEBs. The minimum difference between the produced and the consumed energy for each building was defined for each European country, since the climate, construction technology, occupant behavior and countries regulations differ between these countries. These values are listed in Table 1. 
Table 1: Minimum Difference Between Produced and Consumed Energy NZEB [13]

\begin{tabular}{cccc}
\hline \multicolumn{1}{c}{ Category } & \multicolumn{2}{c}{ EE threshold } & Country \\
\hline & Heating & Cooling & \\
\hline Energy efficiency & $80 \mathrm{KWh} / \mathrm{m} 2$ & $80 \mathrm{KWh} / \mathrm{m} 2$ & Belgium Flanders, Portugal, Greece, France, Spain \\
\hline Low-energy & $60 \mathrm{KWh} / \mathrm{m} 2$ & $60 \mathrm{KWh} / \mathrm{m} 2$ & Greece, France, Spain \\
\hline Ultra-low energy & $30 \mathrm{KWh} / \mathrm{m} 2$ & $30 \mathrm{KWh} / \mathrm{m} 2$ & Austria, Netherlands, Italy \\
\hline Passive Standard & $15 \mathrm{KWh} / \mathrm{m} 2$ & $15 \mathrm{KWh} / \mathrm{m} 2$ & Belgium Wallonia \\
\hline
\end{tabular}

According to European commission for energy all EU countries should design new buildings to be nearly zero-energy buildings by 31 December 2020. For Jordan, minimum ZEBs thresholds are not set yet. Also, there is still a lack of knowledge on the economic and social feasibility of using green buildings in Jordan. Next sections discuss the research methodology and the results of this study.

\section{Methodology}

This section explains the methodology used in this study to simulate the energy of the case study building. Different design scenarios were compared and assessed using a computer simulation program. Information about each scenario regarding its technical specification and cost was obtained from 3-4 local construction companies.

\subsection{Case Study}

The methodology proposed in this study was applied to a typical low-rise residential building. The building is located in Abu Nusair area in Amman, with total area of $393 \mathrm{~m}^{3}$, which represent the average area of newly constructed villas in Amman [14]. The building was designed according to Jordanian engineering design codes, with footprint shown in Figure 1. The building is a single-family villa that consists of two stories above ground and one basement. The services for the building are located at the basement and at the roof. In the basement, there is a fuel tank, pump, and diesel boiler, while on the roof there is a complementary water tank. Underground tank is filled once a week by the government-supplied water, then the water is pumped and stored in the roof tank. The construction material is reinforced concrete with external finish as stone veneer, flat roof and $4 \mathrm{~m}$ floor height. For this study, family size of 5 person was considered based on the national average family size of 4.8 people [15], therefore, an average density of 79 $\mathrm{m}^{2} /$ person in the heated apartments. 


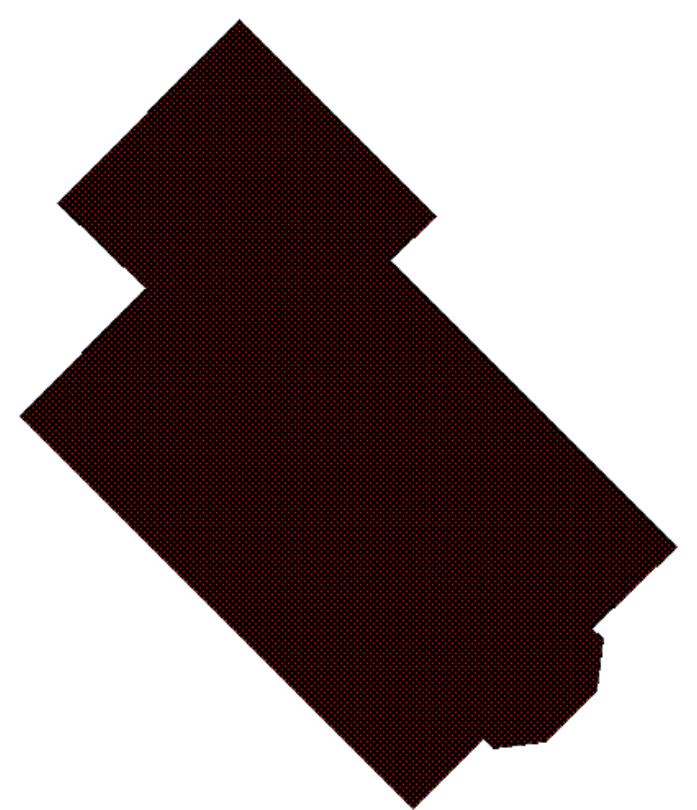

Figure 1. Case study footprint

In addition, based on 2012 Population Census about 50\% of residence are younger than 45 years, among them $21 \%$ are younger than 15 years old. Therefore, most of the apartment occupants would be away from home between 08:00 and 15:00 on weekdays, while, almost all residents would stay at home after 23:00. Also, the majority of residents would stay at their houses on weekend (i.e. Friday and Saturday).

\subsection{Energy Simulation}

Equest 3-65 a free energy simulation software used in this study to assess the thermal comfort and energy performance of different design alternatives [16]. The model developed on three scenarios; 1) model the selected case study building; 2) enhance building design to achieve code compliance; and 3) introduce design strategies to achieve near zero energy building. First, the case study building was modeled to create a base case model used to measure the impact of changes in scenario 2 and 3 explained above on the building thermal performance. The base case characteristics is summarized as follow:

1. The roof ceiling was constructed from $250 \mathrm{~mm}$ reinforced concrete. The ceiling is covered by $25 \mathrm{~mm}$ plastering and $0.5 \mathrm{~mm}$ emulsion paint from inside, and by $60 \mathrm{~mm}$ sloping lightweight concrete from outside, and there was not thermal or water insulation for the roof.

2. The external wall was constructed from limestone, followed by plain concrete, polystyrene, hollow concrete block, plastering and emulsion paint.

3. The ground floor is a slab on grade with 6 in. thickness with no finishing or insulation.

4. Single glass low emissivity clear glass is used for all windows with aluminum frame. 
5. Electricity is consumed by interior Neon Lighting, microwave, iron, kettle, TV, modem and washing machine with total density of $6.13 \mathrm{w} / \mathrm{m}^{2}$.

6. The HVAC system consists of diesel boiler for heating, while there is no source for cooling. Also, there is gas water heater used during cold weather and solar water tank used to heat water during sunny weather.

7. The windows are operable for all rooms except for bathroom and kitchen where windows are curtainwall type with a fan for ventilation. Operable windows are closed at night in winter and manually opened when cooling is needed. No mechanical ventilation is provided and there are 4 standup fans.

The second scenario was to enhance the design of the building based on code compliance. At this scenario, envelope conductivity was first improved to satisfy the code requirement of $1.6 \mathrm{~W} / \mathrm{m} 2$ $\mathrm{K}$. this was done by changing the type of windows to double clear and low emissivity (e). Also, Expanded Polystyrene (EPS) thermal insulation where installed at the roof covered by sand, cement mortar and ceramic tile. Finally, windows frames were changed to have sealed breaks,. The final scenario defines new design strategies in order to achieve a near zero energy building. The first strategy is to improve thermal resistance for the insulation of the building envelope. Next, more energy-efficient lighting system is installed with intensity of $4.6 \mathrm{w} / \mathrm{m}^{2}$. Also, skylight with coverage of $33 \%$ where installed in the building, and window-to-wall ratio increased to $20 \%$ in all direction. In addition, overhangs were added on the southern elevation and fins were added on eastern and western elevations. Moreover, low-e double glazing is installed with $\mathrm{e}=0.04$ filled with argon gas to fill the gap between windows panes. Finally, photovoltaic panels are installed to produce electricity.

To evaluate the electricity bill according to the National Electricity Company, the tariffs per kilowatt-hour consumption are listed in Table 2.

Table 2. Electricity tariffs

\begin{tabular}{cc}
\hline Block (kwh/month) & Tariffs $(\mathbf{\$} / \mathbf{k w h})$ \\
\hline $\mathbf{1 - 1 6 0}$ & 0.046 \\
\hline $\mathbf{1 6 1 - 3 0 0}$ & 0.1 \\
\hline $\mathbf{3 0 1 - 5 0 0}$ & 0.12 \\
\hline $\mathbf{5 0 1 - 6 0 0}$ & 0.16 \\
\hline $\mathbf{6 0 1 - 7 5 0}$ & 0.22 \\
\hline $\mathbf{7 5 1 - 1 0 0 0}$ & 0.26 \\
\hline $\mathbf{1 0 0 0}<$ & 0.37 \\
\hline
\end{tabular}

In addition to electricity bill, life cycle cost analysis was conducted to evaluate each energy strategy with respect to its life cycle cost along with energy saving. The cost of each energy strategy is determined by consulting 2-3 local specialized companies and consider the average prices. The collected prices include: 
1. initial cost,

2. expected number of repair and replacement along with their cost through their useful life. In this study, only few components in the building required maintenance/ repair or replacement include: a. clean building façade every 7 years; b. maintain windows every 5 years on average. Roof finishing requires repair every 15 years and walls internal finishing will require maintenance every 7 years. Finally, diesel boiler requires maintenance every 3 years.

3. electricity cost as listed in Table 2 with escalation rate estimated based on the average value of last 10 years $(3 \%)$, and residual values of materials and building components.

LCC calculation performed using real discount rate of $0.3 \%$ based on the Central Bank of Jordan and the analysis were performed on 25 years period.

\section{Results}

Monthly energy consumption and gas consumption for the case study building from each analysis scenarios are shown in Figure 2 through Figure 4. Results show that electricity consumption from scenario 1 is the lowest and equal 12,700 KWh/year, electricity consumption from scenario 3 is the highest and equal $16,690 \mathrm{KWh} /$ year, and electricity consumption from scenario 2 is equal $16,580 \mathrm{KWh} /$ year. The increase in energy consumption for the second and the third analysis scenarios can be explained by increasing the comfort conditions and installing mechanical ventilation in these scenarios to comply with the Jordanian Thermal Insulation Code Requirements (JNBC 2009). Also, the increase in electricity consumption from the third scenario compared to the second scenario is explained by adding skylight on the roof of the building.

On the other hand, almost inverse relation can be observed for the gas consumption between the three scenarios. First, the results from analyzing the first scenario show that the amount of gas consumption for this scenario is 1.84 bigger than the consumption obtained from scenario 2 and 1.69 bigger than the consumption obtained from analyzing scenario 3 . These results can be explained by the absence of insulation at the roof and at exterior wall. However, the higher value of gas consumption resulted from analyzing scenario 3 comparing with that resulted from analyzing scenario 2 is explained by adding the skylight which increase the heating load in winter. Regarding the photovoltaic, it was recommended by the national electric power company to install PV System with capacity of $11 \mathrm{kw}$. The system will run at maximum and the extra electricity from the building demand will be taken by the national electric power company, and in return the company will not generate any electricity bill for the building. 


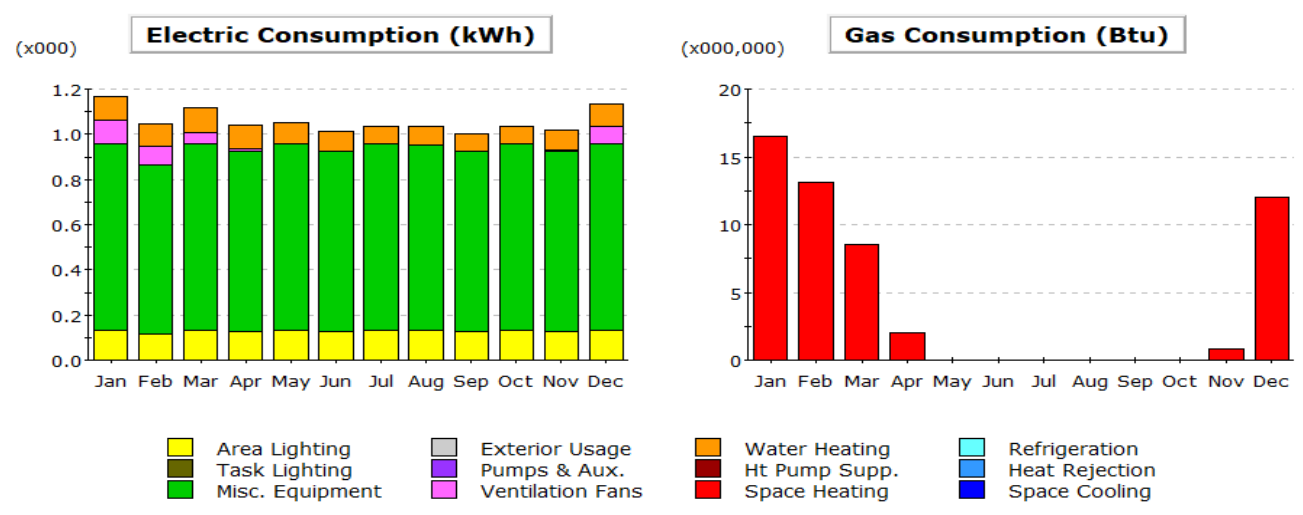

Figure 2. Monthly electric consumption and Gas consumption from base case building
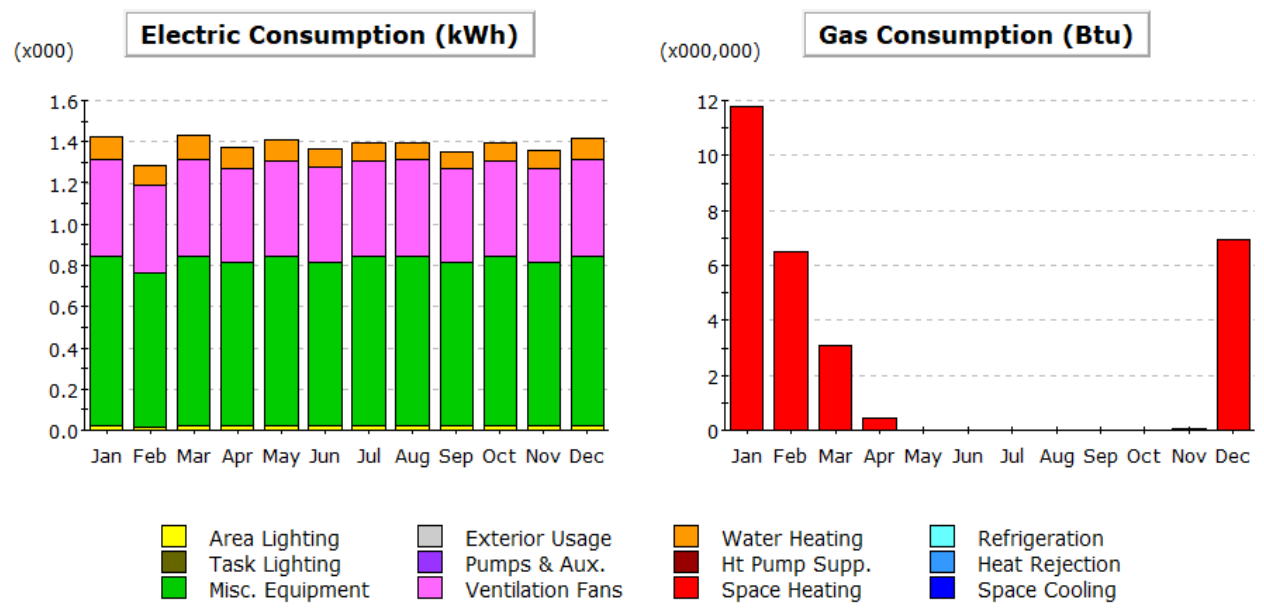

Figure 3. Monthly electric consumption and Gas consumption from code compliance building

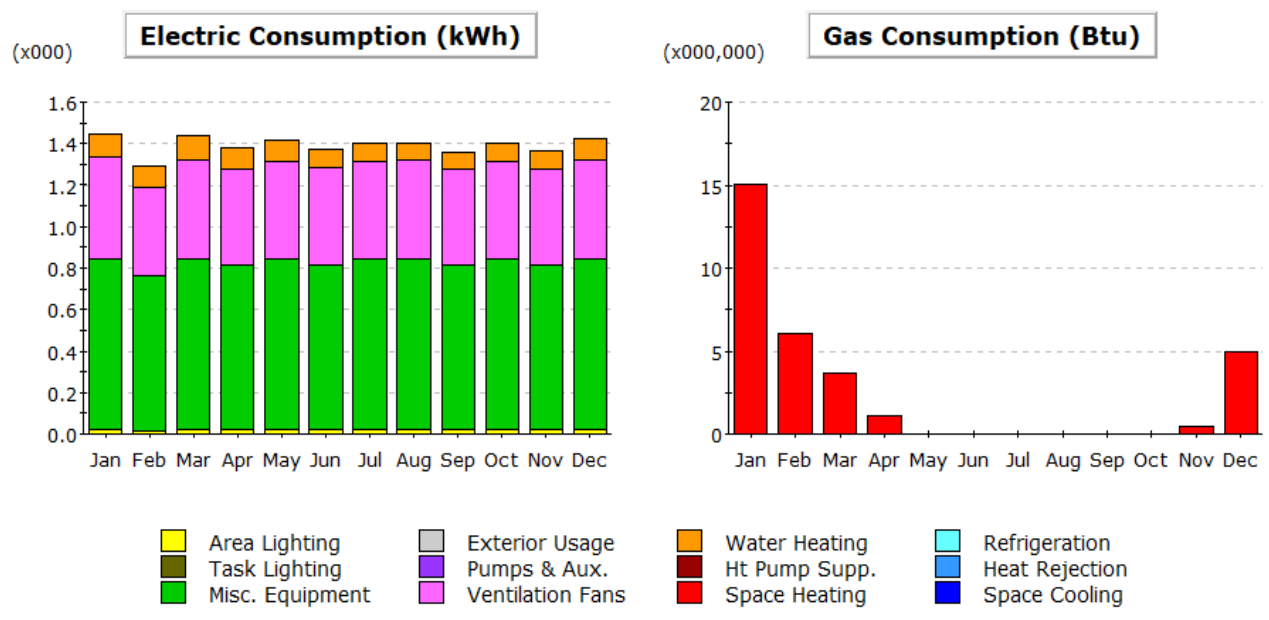

Figure 4. Monthly electric consumption and Gas consumption from scenario 3 
The results from life cycle cost analysis are shown in Table 3. From the Table it's clear that the life cycle cost for scenario 3 is the lowest due to the use of PV, while achieving code requirements results in the highest life cycle cost (i.e. 1.09 times the life cycle cost for the base case building).

Table 3. The results of LCC analysis

\begin{tabular}{|c|c|c|c|}
\hline & Scenario 1 cost $(\$)$ & Scenario 2 cost $(\$)$ & Scenario 3 cost $(\$)$ \\
\hline Envelope Airtightness & - & 1200 & 1200 \\
\hline Roof & 4400 & 6370 & 7900 \\
\hline external walls & 3750 & 6200 & 8020 \\
\hline Windows & 18542 & 26410 & 50214 \\
\hline lighting & 5100 & 7300 & 7300 \\
\hline HVAC & & 45000 & \\
\hline Ventilation & - & \multicolumn{2}{|c|}{6500} \\
\hline PV & - & - & 10000 \\
\hline Apartment Cost & & $\$ 1000 / \mathrm{m}^{2}$ & \\
\hline Electricity Cost (25 year) & 54250 & 90200 & zero \\
\hline Thermal Cost (25 years) & 15732 & 8538 & 9256 \\
\hline $\mathbf{L C C}$ & 539774 & 590718 & 538390 \\
\hline
\end{tabular}

\section{Conclusions}

The main objective of this study is to assess different design strategies and provide the best strategies that leads to minimum energy consumption with minimum life cycle cost. Several design scenarios were tested in search for best strategies to satisfy code requirement and reach zero energy consumption, then the life cycle cost for each scenario is evaluated. The selected design scenarios were applied to a base case single family two stories building. The building is already built, therefore, in this study there was limitation on the design parameters that can be changed including building orientation and window to wall ratio. These parameters may consider in future work along with the parameters considered in this study. Also, since the base case building is single family the whole area of the roof was used to install the PV system, however, in multifamily building the roof is shared between all residents, therefore, there is a limited space to install PV system. A solution for this issue needs to be investigated in future research. The main finding of this study indicates that installing PV system results in minimum energy consumption and minimum life cycle cost despite the large initial value of the PV system. however, this conclusion remains theoretical unless the limitations of the LCC analysis performed in this study is investigated. One of these limitations is investigating the benefits of thermal or electric energy demand reduction on the overall environmental cost and society benefit in monetary terms.

Another finding of this study was that good envelope conductivity and airtightness largely reduce heating load.

The recommendation of this study includes: 
1. develop a methodology to assign the comfort and heating set point for residential buildings since no such methodology is developed in Jordan.

2. Create a structured rating program focusing on Energy Efficiency in buildings.

3. Give incentive to owners and investors to improve energy performance for buildings in Jordan

\section{Acknowledgements}

We thank all the experts contributed to this research including Professor Ahmad alzoubi from the electrical department at Yarmouk university, Eng. Ahmad Hyari, Eng. Mohammad thiabat, and Eng. Ibrahim khasawneh. Also, we thank the following companies including Sawsana company, Meyahuna company, and Abu Alhija company for assistance with specifications and prices of different materials used in the model.

\section{References}

[1] RECREEE, 2016, Energy Profile of Jordan, The Regional Center for Renewable Energy and Energy Efficiency (RCREEE), Nasr City, Cairo, Egypt.

[2] McNichol, E. (2016). It's Time for States to Invest in Infrastructure. Washington DC: Center on Budget and Policy Priorities.

[3] Attia, S., 2016, Zero Energy Building design in Hot Climates Workshop, available from http://www.shadyattia.net/academic/WorkshopZEB/index.html, Accessed: 01.04.2018

[4] Al Tarabsheh, A., \& Ababne, M. (2010). Analysis of solar radiation in Jordan. Jordan J Mech Ind Eng, 4(6), 733-737.

[5] Al-Sallami, H., 2015, Analysis of Energy Use Intensity in Residential Buildings in Jordan, Master Thesis, German Jordanian University.

[6] JNBC, 2009. Thermal Insulation Code, Jordanian National Building Council, 2nd edition, Amman, Jordan.

[7] Greenpeace 2013. Jordan's Future Energy. Available at: http://www.greenpeace.org/arabic/PageFiles/481146/Jordan_Report2013.pdf.Accessed: 01.04.2018

[8] IEA SHC Task 40, 2013. Towards Net Zero Energy Solar Buildings. http://task40.ieashc.org/Data/Sites/11/documents/ebc_annex_52_factsheet.pdf. Accessed: 03.04.2018

[9] Crawley, D., Pless, S. D., \& Torcellini, P. A. (2009). Getting to net zero. National Renewable Energy Laboratory. 
[10] Parliament, E. U. (2010). Directive of the European Parliament and of the council on the energy performance of buildings (recast).

[11] Visscher, H., Mlecnik, E., \& Meijer, F. (2009, December). The impact of energy performance regulations on systems of building control. In RICS, COBRA Research Conference, University of Cape Town (Vol. 10, pp. 1356-1367).

[12] Peterson, K., Torcellini, P., Grant, R., Taylor, C., Punjabi, S., \& Diamond, R. (2015). A common definition for zero energy buildings. Prepared for the US Department of Energy by The National Institute of Building Sciences, US Department of Energy.

[13] ZEBRA 2020 Data Tool, 2016, Energy efficiency trends in buildings. Available from: http://www.zebramonitoring.enerdata.eu/overall-building-activities/nzeb-definitions-by-country.html, Accessed: 4.04.2018.

[14] Jordan Housing Development Association, reports, 2016

[15] Jordan Department of Statistics, Building Permit Report Nov. 2015.

[16] DOE, 2016. EnergyPlus [online]. Available from: https://www.doe.gov.ph/transparency/2016-annual-report. Accessed 1.04.2018. 